\title{
THE INDIVIDUAL SECTOR OF AGRICULTURE IN MOLDOVA AND ITS CONTRIBUTION TO THE DEVELOPMENT OF RURAL AREAS
}

\author{
Liliana CIMPOIES, Department of Economic Theory and Policies, Faculty of General Economics and Law, Academy of Economic \\ Studies of Moldova, Bodoni 61 st., Chisinau, Moldova, 1.cimpoies@ uasm.md. (corresponding author) \\ Elena SEMENOVA, Department of Business Administration, Faculty of Economics, State Agrarian University of Moldova, \\ Mircesti 42 st., Chisinau, Moldova, semionov777@mail.ru
}

\begin{abstract}
Moldovan agriculture is still characterized by a pronounced structural dualism with a very large number of small-scale family farms. The accentuated poverty makes rural economy to flow more and more to a natural subsistence economy, isolating itself from the market economy. The scope of the paper is to assess the farm performance and its contribution to the development of rural areas. The research analysis is based on national statistics and survey data of 723 farms. In order to assess farm performance technical efficiency (TE) and stochastic frontier analysis is used. The contribution of different types of income on the farm development level is analysed through regression analysis. Increasing of farm performance through a higher efficiency and competitiveness could be regarded as the key solution to the low income problem of rural families.
\end{abstract}

Keywords: agriculture, family farms, rural development.

\section{INTRODUCTION}

It is commonly believed that agriculture in agri-food industry economies is the backbone of the rural space. None of the rural development programs could be developed without agriculture taken into consideration. Although many changes taken place in the role and obligations of agriculture, the latter remains to be the core of program of rural development. In the meantime, the problem of a new philosophy in agricultural development appeared, conducting to the idea of changing the gravity centre from the productivity aspect to its multifunctional aspect (Otiman, 2011).

Rural is usually understood as a spatial concept, most simply defined as all that is not urban. Rural has been identified with the countryside, agriculture, traditional culture, and geographic peripherally. However, such simplistic definitions fail to take into consideration the complexity that is encompassed in rural (Callanan et al., 2006).

A sustainable development of rural areas is based on the definition of rural areas, given in the European Charter of Rural Areas (ECRA), according to which: "Europe's countryside is a historical and precious cultivated landscape in which people live and work and whose maintenance is an important social issue, yet is also of economic value".

The traditional socialist thinking believed in economies of scale and thus gave preference to large corporate farms. The Western market-oriented thinking attaches more importance to individual incentives and thus emphasizes the advantages of smaller family farms. Gorton and Davidova (2004) note that, contrary to prior expectations, there is no clear-cut empirical evidence in transition economies that family farms are more efficient than corporate farms in all farming activities. While significant differences have been found in favour of family farms against the average corporate farm, the best corporate farms still tend to perform as well as the best family farms.

The optimum farm size is difficult to define because opinions about the farmers' objective function differ and because the same determinants can affect farm size in different ways across different farms or countries (Koester, 2003). The optimality of farm size for a given country is largely an empirical question (Swinnen, 2006). In general, the optimal farm size is a relative notion that depends on the local conditions, such as the share of rural population and the land endowment.

Once the investigations will show the best type of holdings from the perspective of sustainable rural development, it is necessary to find out how to make it efficient and competitive.

Being efficient, according to Greene (1997) is when "producers ... have produced as much as possible with the inputs they have actually employed and if they have produced that output at minimum cost ". Competitiveness, according to Sharples and Milham (1990) is: “...the capacity to sell goods and services at the right moment of time, place and in a favourable way for foreign buyers, at prices which are equal or smaller than those offered by other potential suppliers, earning at least the opportunity cost of the used resources".

Moldovan agriculture is still characterized by a pronounced structural dualism with a very large number of smallscale family farms at one extreme and the relatively small number of large corporate holdings, like agricultural production 
cooperatives and limited liability companies, at the other. More than fifteen years after the land reform has been launched, markets have not fully developed yet and market - based middle-sized individual holdings are rare: "medium-sized" family farms, the backbone of any market agriculture, virtually do not exist in Moldova. Most of individual farms, small by size produce only for own family consumption and cannot find their way to the market place. The accentuated poverty makes rural economy to flow more and more to a natural subsistence economy, isolating itself from the market economy.

\section{RESEARCH METHODS}

Research tasks and objectives.

The aim is to assess the farm performance and its contribution to the development level of rural areas. The objectives of the study are to assess the contribution of agricultural sector to economic development, to analyse the influence of different factors of influence including incomes, farm area, production costs on the farm technical efficiency.

Research methods.

The research analysis is based on national statistics and survey data. The research is part of the Academy of Sciences project "Sustainable rural development in Republic of Moldova in the context of EU accession". In the project were surveyed 938 individual farms from nine districts across the country.

The analysis is based on the following methods: comparative, logical analysis, linear regression. In order to assess farm performance technical efficiency (TE) and stochastic frontier analysis is used. The influence of different factors (incomes, costs, farm area) on farm technical efficiency and the contribution of various types of income on the farm development level is analysed through regression analysis.

\section{RESULTS AND DISCUSIONS}

\section{The contribution of agriculture to economic development in Moldova}

Despite the diminishing trend in the share of agriculture in GDP (from $30 \%$ to 12\%) the contribution of agriculture is much higher than only its direct share in GDP. This fact is related to the large share in GDP of food industry, beverages and tobacco $(24 \%$ and $10 \%)$. In the same time, one third of population is employed in agriculture, and more than half of the population live in rural areas (Figure 1).

The contribution of the agricultural sector at the value added was about $16 \%$ in 2014 , twice more that its level in 2008 (Figure 1). This increase was due to the growth in the value of agricultural production. An exception was registered in 2012, very unfavorable year for agriculture, due to its particular weather conditions (droughts in late autumn and late spring frosts). The high contribution of agriculture to the value added refers to its particular role in poverty reduction and development of rural areas.

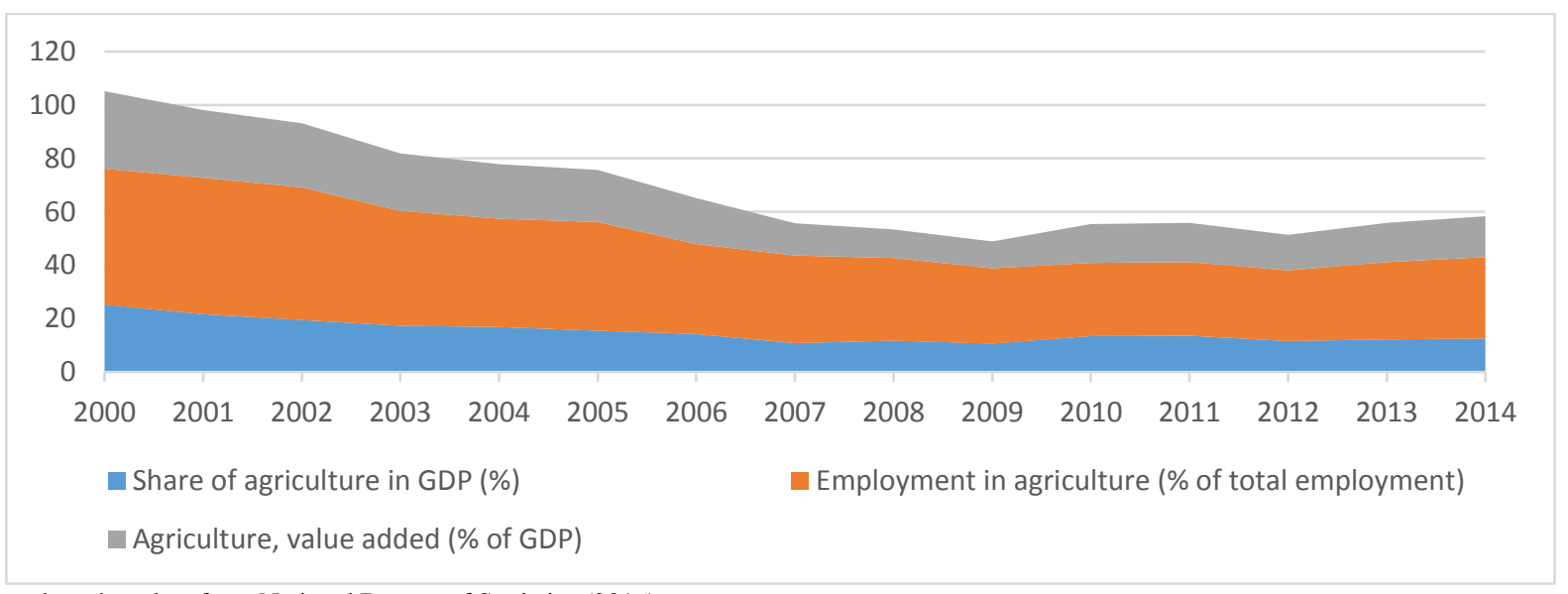

Source: based on data from National Bureau of Statistics (2016)

Figure 1. The contribution of agriculture to economic development of Moldova

The agricultural development is influenced by the structure and use of land. The small farms have a larger share of manual work, thus increasing the land productivity can contribute to development of rural areas and poverty reduction. According to the National Bureau of Statistics almost half of the agricultural land is used by farms and households with an average land area of less than 10 hectares.

According to the results of the General Agricultural Census (GAC) 2011, in Moldova are registered 902210 agricultural holdings, from which the majority (99.6\%) do not have juridical status and only $0.4 \%$ (53577) of agricultural holdings have juridical status. From the total amount of holdings, 848637 are active holdings (that uses agricultural land and/or grow livestock and/or poultry) and 53577 were registered and temporarily not active holdings. Agricultural holdings own 2243540.02 hectares, from which the utilized agricultural area (UAA) is of 1940135.56 hectares, distributed to 846981 holdings. The average size of UAA per holding is of 2.29 hectares. The size is close to the $49 \%$ of the EU-27 agricultural holdings, which during the 2010 census had and an average size of less than 2 hectares. According to the census data, the UAA per capita is of 0.54 hectares, also near the EU-27 average ( 0.3 hectares UAA per capita). From the 
total area about $57 \%$ is used in full ownership of the land by $97.2 \%$ of holdings, about $25 \%$ is fully leased and used by $0.3 \%$ of holdings and $15 \%$ is used by $1.4 \%$ of holdings under mixed land ownership (both ownership and lease). The other $3 \%$ of the area is used by $1.1 \%$ of holdings under other type of land ownership.

The UAA distribution according to the size classes of total area is not homogenous. From the Census results, the highest share of holdings is grouped under the smallest land size classes. Thus, $71 \%$ of agricultural holdings have less than one hectare, but the utilized area is 10.1 of total UAA. Holdings with $1-5$ hectares (27\%) utilizes $19.3 \%$ of total UAA. On the other side are the $0.3 \%$ of agricultural holdings with large sizes (at least 100 hectares) and utilizes $63.4 \%$ of the UAA. Almost $73 \%$ of total UAA is arable land, which is above the EU-27 average (60\%) (NBS, 2011).

\section{Farm efficiency and incomes in rural areas}

An important role in agricultural and rural development is related to farm efficiency. The farms competitive advantage results from the efficient use of factors. The term of efficiency includes technical, allocative and social efficiency (Ratinger, 2001). One of the most important methods to assess economic efficiency includes two components: technical efficiency and allocative efficiency (Farell 1957). According to Farrell the technical efficiency is represented by the ratio between actual and frontier output

$$
T E(y, x)=\frac{y}{f(x)}
$$

Where $\mathrm{y}$ represents the output and $\mathrm{x}$ is a vector of inputs. Technical efficiency can take values between 0 and 1 . Technical efficiency reflects the farmers' ability to obtain a maximum amount of output using a set of inputs. We use further technical efficiency to appreciate the farm development level.

According to the obtained results of the analyzed sample (723 farms), the average value of technical efficiency is 0.538. It indicates to an average performance level of the farms included in the survey. The maximal value of technical efficiency reaches 0.874 while the minimum value is 0.044 .

Increasing of farm performance through a higher efficiency and competitiveness could be regarded as the key solution to the problem of low income of rural families. However, increasing of efficiency and competitiveness of family farms is not an easy task, as it requires serious structural changes within agricultural sector.

To analyze which factor influenced the most on farm performance level the regression analysis is used (Table 1).

Table 1. The influence of the main coefficients of multiple regression on farm technical efficiency

\begin{tabular}{|c|c|c|c|c|}
\hline $\mathrm{Y}$ & $\mathrm{R}$ & $\mathrm{R}$ squared & Factors of influence & Beta coefficient \\
\hline \multirow{2}{*}{$\begin{array}{c}\text { Technical } \\
\text { efficiency TE }\end{array}$} & \multirow{3}{*}{0.679} & \multirow{2}{*}{0.461} & Incomes & 0.812 \\
\cline { 3 - 4 } & & & Farm Area & 0.069 \\
\cline { 3 - 4 } & & & Production Costs & -0.354 \\
\hline
\end{tabular}

Source: own calculations

The results of the regression analysis demonstrate an average strong correlation between the farm technical efficiency and the analyzed exogenous factors. In the same time, the value of the multiple determination coefficient $\left(\mathrm{R}^{2}=0,46\right)$ indicates to the farm technical efficiency variation by the influence of the examined factors of about $46 \%$. The analysis of factors of influence on the technical efficiency demonstrates that a higher impact has the received incomes $(0,81)$ (Figure 2).

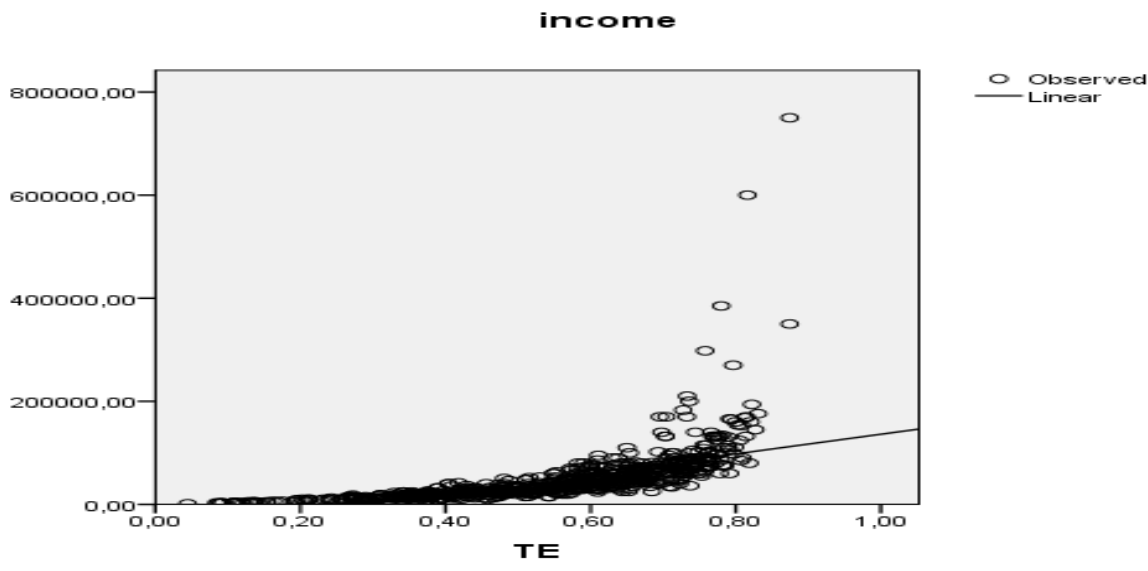

Figure 2. Influence of income on farm technical efficiency level

According to the data of National Bureau of Statistics the disposable income of population from rural areas experience a decreasing tendency. The highest incomes are from salaries (28\%). Incomes from individual agricultural activity decreased from $34.8 \%$ in 2006 to $17.5 \%$ in 2015 . The incomes from remittances account $23.4 \%$ from total population incomes. According to a recent research, about $10 \%$ from remittances are directed to investments in 
agricultural holdings, for purchasing new agricultural land, buildings or machinery. Due to lack of working places and the increased rate in inactivity, the share of labor incomes was mostly from non-agricultural sector through an increase in salaries. The fast increase in incomes from non-agricultural compared to agricultural activities lead most of employed agricultural workers among the $40 \%$ of country's poor population.

Agricultural incomes were affected by various fluctuations during the analyzed time series which undermined their contribution to the increase of living conditions in rural areas. Thus, incomes diversification should be considered as a source of poverty reduction in rural areas.

In the analyzed survey of 732 farms, a similar situation is observed. The largest share of the incomes received belongs to wages $(31 \%)$, followed by incomes from selling agricultural production (21\%) and money transfers from family (21\%) (Figure 3).

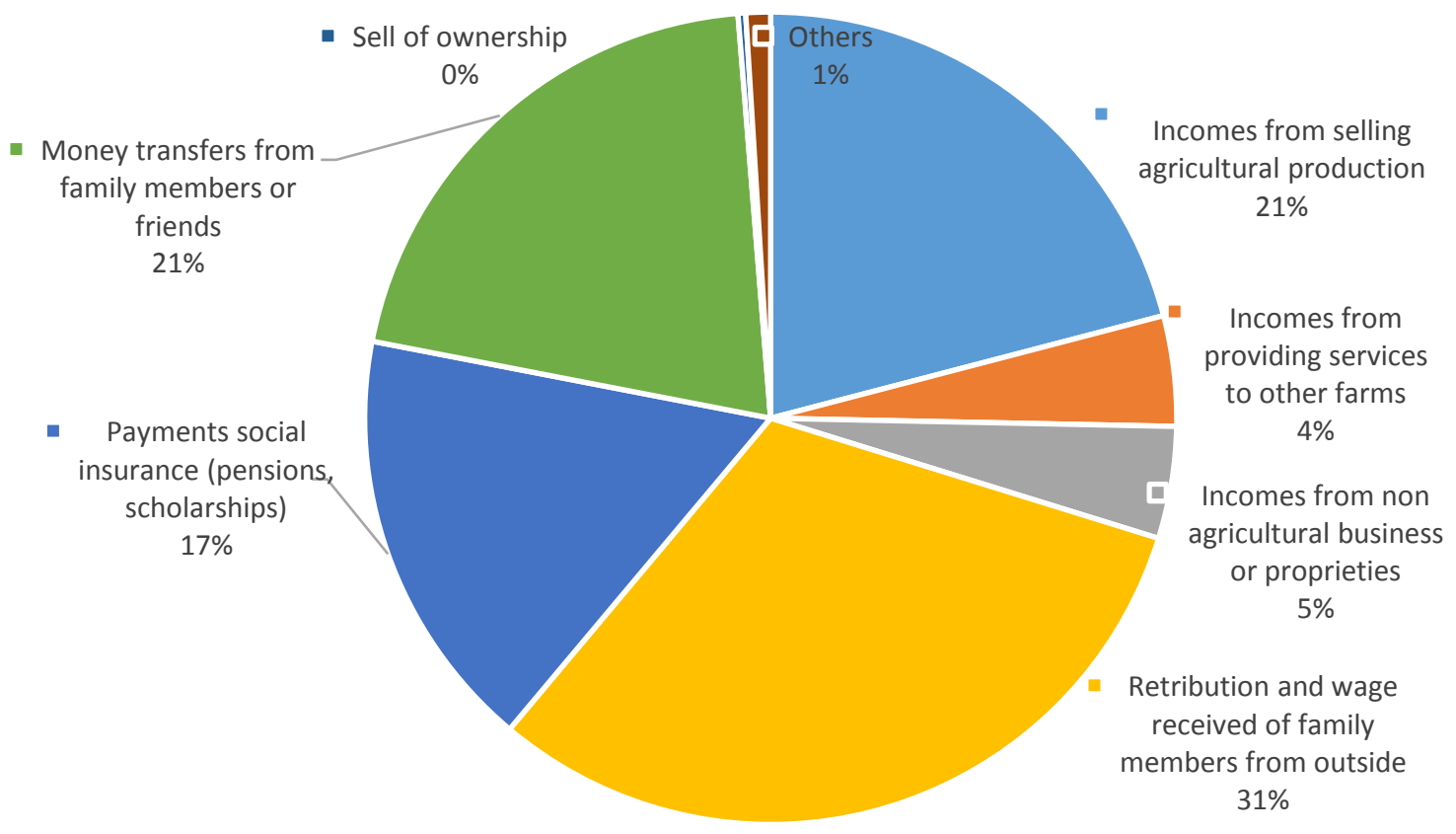

Figure 3. Structure of individual farms incomes

Because income resulted as the factor that most influence has on the farm efficiency level, is important to analyze the type of income which most affects technical efficiency (Table 2).

Table 2. The influence of different types of incomes on farm technical efficiency

\begin{tabular}{|c|c|c|c|c|}
\hline Y & $\mathrm{R}$ & $\mathrm{R}$ squared & Factors of influence & Beta coefficient \\
\hline \multirow{4}{*}{$\begin{array}{c}\text { Technical } \\
\text { fefficiency TE }\end{array}$} & \multirow{4}{*}{0.805} & \multirow{4}{*}{0.649} & Incomes from selling agricultural production & 0.24 \\
\cline { 4 - 5 } & & Incomes from providing services to other farms & 0.203 \\
\cline { 4 - 5 } & & Incomes from nonagricultural business or proprieties & 0.179 \\
\cline { 4 - 5 } & & $\begin{array}{c}\text { Retribution and wage received of family members from } \\
\text { outside }\end{array}$ & 0.584 \\
\cline { 4 - 5 } & & Payments social insurance (pensions, scholarships) & 0.316 \\
\cline { 4 - 5 } & & Money transfers from family members or friends & 0.517 \\
\cline { 3 - 5 } & & Sell of ownership & 0.062 \\
\cline { 3 - 5 } & & Others & -0.097 \\
\hline
\end{tabular}

Source: own calculations

The results of the regression analysis demonstrate a quite strong correlation between the farm technical efficiency and the analyzed exogenous factors. In the same time, the value of the multiple determination coefficient $\left(\mathrm{R}^{2}=0.64\right)$ indicates to the technical efficiency variation by the influence of the examined factors of about $64 \%$. The analysis of factors of influence on the technical efficiency demonstrates that a higher impact has incomes received as wage or other type of retribution (0.58), money transfers from family or friends $(0.51)$ and social insurance payments $(0.31)$.

When existing financial sources are scarce, farmers in order to expand the level of production and/or to use more advanced machines and equipment for an increased level of labor productivity can decide to acquire different types of loans (Figure 4). 


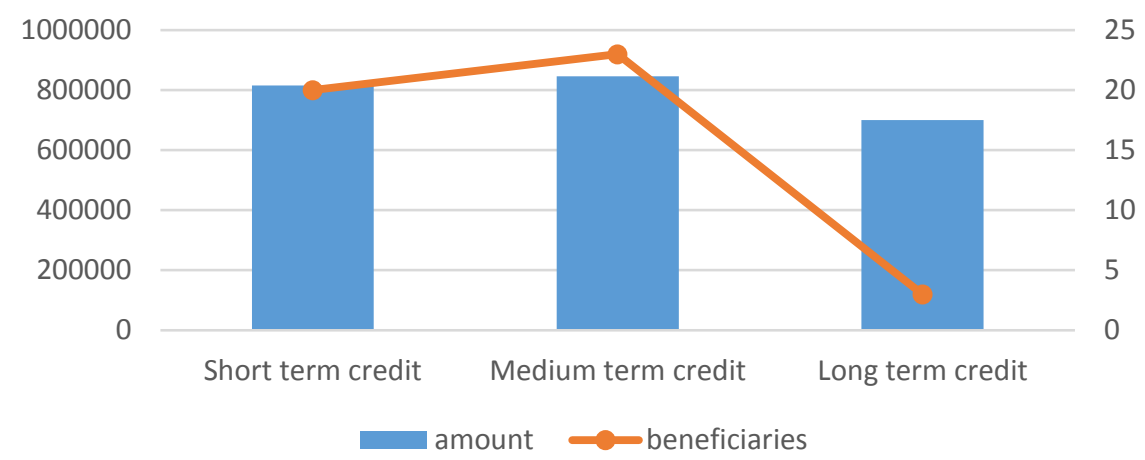

Figure 4. Types and amount of loans obtained by farms

From the surveyed farms, only a few of them chosen to apply for a loan. The total amount of obtained loans was of 2362000 MDL. Most of them preferred a small or medium term loan, while only few considered the long term loans. The interest rates varied between 12 and 26 percent. The fact that determined only a few farms to apply for a loan could be caused by the high interest rates applied on loans in agriculture.

\section{CONCLUSIONS}

In Moldova agriculture plays a key role to development of rural areas. There are a large number of small scale farms, the efficiency of which influence the development of rural areas and poverty alleviation of rural families.

According to the obtained results, the analyzed farms have an average level of development, whose performance could be improved. Its efficiency is mostly influenced by the amount of incomes received. Nevertheless, in rural areas from all incomes only $25 \%$ belongs to agricultural activities, while most of them result from salaries of non-farm employment and money transfers received from relatives, mostly migrated abroad. Thus, analyzing the influences of different incomes of farm efficiency, a higher impact is observed from incomes obtained as wage from family members employed outside farm activity and money transfers received from family members migrated abroad. A solution to improve the farm efficiency is to use alternative financial sources as loans. Nevertheless, only few of surveyed farms have taken a loan, mostly small and medium term at an interest rate between 12 and 26 percent. Increasing of farm performance through a higher efficiency and competitiveness could be regarded as the key solution to the low income problem of rural families.

\section{REFERENCES}

1. Calannan, S., Cuddy, M., Ni Leime, A. 2006. Rural development: policy and institutions. In: Integrated development of Agriculture and Rural Areas in Central European Countries. Lexington Books, Lanham, MD.

2. Parliamentry Assembly. 1996. European Charter for rural areas. Working Document $7507 . \quad$ On-line: http://assembly.coe.int/ASP/Doc/XrefViewHTML.asp?FileID=7441\&Language=EN

3. Gorton, M., Davidova, S. 2004. Farm productivity and efficiency in the CEE applicant countries: A synthesis of results, Agricultural Economics, Vol. 30, pp. 1-16. https://doi.org/10.1111/j.1574-0862.2004.tb00172.x

4. Greene, W. H. 1997. Frontier production functions. In Pesaran, M. H. and Shmidt, P., editors, Handbook of Applied Econometrics, volume II: Microeconometrics. Blackwell Publishers Ltd.

5. Farrell, M. J. 1957. The measurement of productive efficiency. Journal of the Royal Statistical Society, Vol. 120, pp. $253-290$. https://doi.org/10.2307/2343100

6. Koestner, U. 2003. A revival of large farms in Eastern Europe? - How important are institutions? Plenary paper presented at the Conference of International Association of Agricultural Economists, Durban/South Africa, 16.-22/08/2003.

7. Lerman, Z., Csaki, C., Feder, G. 2004. Agriculture in transition: Land policies and evolving farm structures in Post-Soviet Countries, Lexington Books, Lanham, MD.

8. Mathijs, E., Noev, N. 2002. Commercialization and Subsistence in Transaction Agriculture: Empirical Evidence from Albania, Bulgaria, Hungary and Romania. The X-th EAAE Congress 'Exploring Diversity in the European Agri-Food System', Zaragoza (Spain), 28-31 August 2002.

9. National Bureau of Statistics. 2016. Aspects of the population standard of living. National Bureau of Statistics of the Republic of Moldova.

10. National Bureau of Statistics. 2016. Statistical Yearbook of the Republic of Moldova 2016.

11. National Bureau of Statistics. 2011. General Agricultural Census 2011.

12. Otiman, P.I. 2011. Alternativele economiei rurale a României: dezvoltarea agriculturii sau insecuritate alimentară şi deşertificare rurală severă. Editura Academiei Române, Bucureşti, România.

13. Ratinger, T. 2001. Methodology for assessing determinants of competitiveness of Czech, Hungarian and Polish farms. IDARA.

14. Swinnen, J. 2006. Endogenous agricultural structures: Insights from transition countries. The 96th EAAE Seminar Causes and Impacts of Agricultural Structures, Taenikon/Switzerland, 10-11/01/2006. 